\title{
PERFIL ORÇAMENTÁRIO DE PEQUENOS MUNICÍPIOS DO VALE DO MUCURI: $O$ caso de Ouro Verde de Minas
}

\section{BUDGET PROFILE OF SMALL MUNICIPALITIES OF THE MUCUCI VALLEY: The case of Ouro Verde de Minas}

\begin{abstract}
Marcélia Aguiar Ferreira
Administradora, Especialista em Comunicação, Marketing e $\mathrm{RH}$, Coordenadora e Prof ${ }^{a}$. Titular do Curso de Administração da Universidade Presidente Antônio Carlos UNIPACTO - MG - E-mail:

E-mail: marceliaaguiar@hotmail.com

Thiago Gondim

Psicólogo, e licenciatura em História, especializado em Saúde Mental, Estresse e Dependência

Química, Professor na Faculdade Presidente Antônio Carlos de Teófilo Otoni, E-mail: thiagogondim2010@hotmail.com
\end{abstract}

Adriana Aparecida da Conceição Santos Sá

Doutoranda do Programa de Pós-graduação Interdisciplinar em Ciências Humanas da Universidade Federal de Santa Catarina (PPGICH/UFSC). Mestre em Gestão Integrada do Território pela Universidade Vale do Rio Doce - UNIVALE (2014). Especialista em Gestão de Micro e Pequenas Empresas pela Universidade Federal de Lavras - UFLA (2005). Professora Assistente da Universidade Federal dos Vales do Jequitinhonha e Mucuri (UFVJM - Campus do Mucuri) email: admpublica@ead.ufvjm.edu.br

\section{Resumo}

Esse estudo analisa o perfil orçamentário do Município de Ouro Verde de Minas MG, no período de 2000 a 2015, no que se refere à composição orçamentária, em termos das principais fontes de receita e despesas, da classificação por finalidade e por natureza do gasto. Foram analisadas as receitas e despesas com base na Lei de Responsabilidade Fiscal - LRF Trata-se de uma pesquisa descritiva de natureza quantitativa e qualitativa, realizada por meio de dados coletados junto à Secretaria do Tesouro Nacional. Os resultados revelaram que as principais fontes de receitas do município são as transferências intergovernamentais da União e do Estado de Minas Gerais. Identificou-se que as despesas correntes foram crescentes no período analisado e os gastos sociais não ocupam destaque nas despesas municipais.

Palavras-chave: Perfil Orçamentário - Municipal; Ouro Verde de Minas; receita e despesas.

\section{Abstract}

This sudy analyzes the budget profile of the Municipality of Ouro Verde de Minas/MG, from 2000 to 2015 as regards the budget composition, in terms of the main sources of income and expenses, classification by purpose and by nature of the expenditure. Revenues and expenses were analyzed based on the Fiscal Responsibility Law - LRF. This is a descriptive research of quantitative and qualitative 
nature, conducted through data collected from the National Treasury Secretariat. The results found were that the main sources of income of the municipality are intergovernmental transfers from the Union and the State of Minas Gerais. It was identified that the current expenses were increasing in the analyzed period and the social expenses do not occupy prominence in the municipal expenses.

Keyword: Municipal Budgetary Profile; Ouro Verde de Minas; income and expenses.

\section{Introdução}

No contexto federativo brasileiro, conhecer a disponibilidade de recursos financeiros e o perfil das despesas dos municípios é de fundamental relevância para identificação de problemas e levantamento de soluções que integrem a atuação dos poderes municipais, estaduais, federal e, igualmente importante para sociedade. É uma forma de, sobretudo, oportunizar a conscientização fiscal, subsidiar o controle social e promover o exercício da cidadania, face aos instrumentos de planejamento e gestão social.

Segundo Sostemeier (2012), o Orçamento Público é o meio de planejamento das finanças públicas, constituindo-se pelas receitas e despesas públicas. A lei 4.320 de 1.964 estabeleceu a organização das finanças públicas para os órgãos públicos. No âmbito das Finanças Públicas, o orçamento tem a função de nortear as atividades do governo nas três esferas, bem como autarquias e empresas públicas. A lei complementar 101, de 2000, também chamada Lei de Responsabilidade Fiscal - LRF impõe maior responsabilidade aos gastos dos recursos públicos, ao estabelecer limites para alguns gastos e indicadores de gestão. Associado a isso, a autora destaca a importância da gestão pública profissional, capacitada para planejar e gerir os recursos públicos.

Ainda segundo Sostemeier (2012, p. 14), no planejamento é necessário estabelecer objetivos e metas plausíveis, que possam ser atingidos, que sejam viáveis e desejáveis. Como Russel (1975) argumenta, o planejamento deve ser baseado na crença de que o futuro pode ser melhorado por uma intervenção ativa do presente, então ocorre a previsão do que deverá acontecer se nada for feito. Russel (1975, p.1) destaca que "o planejamento é a definição de um futuro desejado e de meios eficazes de alcançá-lo [...]". Com isso destaca-se que é necessário planejar, mas também é necessário saber utilizar esta ferramenta para as tomadas de decisões, bem como para gerenciar a administração Pública. 
No contexto de legalidade e obrigatoriedade, como cita Quintana (2011, p.6):

O planejamento pressupõe estratégias, ou seja, o futuro da empresa, o longo prazo, os objetivos a serem alcançados, o que se pretende atingir. $\mathrm{Na}$ entidade pública essa premissa torna-se mais que fundamental, pois, além de ser uma determinação legal, trata-se de bem gerir os recursos públicos, por meio de uma gestão fiscal responsável.

Entende-se que o Orçamento Público com fundamentação na Lei Complementar 101/2000, Lei federal 4.320/1964, com plano plurianual (PPA), a Lei de Diretrizes Orçamentárias (LDO) e a Lei Orçamentária Anual (LOA), contêm os elementos necessários a discriminação da receita e despesa de forma a evidenciar a política econômica financeira e o programa de trabalho do governo. O Município, Estado ou ente Federado deve estar em consonância com a Lei Complementar 101/2000 e atuando de acordo com as necessidades sociais.

Os principais pontos da Lei de Responsabilidade Fiscal (LRF) são: estabelece limites para despesas com pessoal e para dívida pública; determina que sejam criadas metas para controlar receitas e despesas. No orçamento público municipal são definidos como, quando e onde os recursos do município serão aplicados. Além disso, segundo a LRF, nenhum governante pode criar uma nova despesa continuada (por mais de dois anos), sem indicar sua fonte de receita ou sem reduzir outras despesas já existentes. O objetivo é assegurar o pagamento das despesas em cada gestão, sem comprometer o orçamento ou orçamentos futuros.

Considerando finanças públicas e orçamento público, esse estudo traz como problematização: Qual o perfil orçamentário (principais fontes de receita e destino de despesas) do município de Ouro verde de Minas/MG no período de 2000 a 2016 ? O Os objetivos consistiram em: (a) identificar a composição orçamentária do município, quanto às principais fontes de receita e despesas, em termos da classificação por finalidade do gasto e por natureza do gasto; e (b) avaliar a distribuição orçamentária, diante do que estabelece os limites previstos na legislação vigente.

O contexto federativo brasileiro, de acordo o Instituto Brasileiro de Geografia e Estatística-IBGE, atualmente, conta com 5.570 municípios. Desse total, 853 (15,53\%) estão localizados em Minas Gerais, o Estado com maior número de municípios no Brasil (IBGE, 2010). Na divisão político-administrativa, estabelecida pelo IBGE, o Estado encontra-se dividido em 12 mesorregiões: Noroeste de Minas, Norte de Minas, Jequitinhonha, Vale do Mucuri, Triângulo Mineiro/Alto Parnaíba, 
Central Mineira, Metropolitana de Belo Horizonte, Vale do Rio Doce, Oeste de Minas, Sul/Sudoeste de Minas, Campo das Vertentes e Zona da Mata. Cada mesorregião se subdivide em microrregiões, sendo 66 em Minas Gerais. A mesorregião do Vale do Mucuri situada na região nordeste do Estado está subdivida em 2 microrregiões: Nanuque e Teófilo Otoni. A microrregião de Teófilo Otoni é composta por treze municípios, sendo: Ataléia, Catuji, Ladainha, Itaipé, Franciscópolis, Frei Gaspar, Malacacheta, Pavão, Poté, Novo Oriente de Minas, Ouro Verde de Minas, Satubinha e Teófilo Otoni (IBGE, 2010).

O objeto de estudo deste trabalho é o município de Ouro Verde de Minas. O início do povoamento no município deu-se em meados de 1930, quando João Rodrigues dos Santos, José Davi, José Cassiano Bastos, Benício José Ferreira, Henrique Capitólio e Henrique Caporanga, à procura de terras férteis para cultivo do café, se estabeleceram no local, iniciando a formação do pequeno povoado, atual cidade. O topônimo originou-se da grande produção cafeeira considerada o "ouro verde" do município. O distrito foi criado em 1953, com território desmembrado do município de Ataléia. Emancipado em 1962, passando a condição de município.

A área na unidade territorial em 2015: 175.482: $\mathrm{km}^{2}$; no último Censo possuía 6.016 habitantes, com densidade demográfica 2010 (hab/ $/ \mathrm{km}^{2}$ ): 34,28. Destaca-se que entre 2000 e 2014 a população reduziu em torno de 35\%,com PIB per capita de $\mathrm{R} \$ 6.607,95$ (IBGE, 2014). Percentual as receitas oriundas de fontes externas (2015) perfazendo 96,70\%. Conforme o ranking do Índice de Desenvolvimento Humano Municipal - IDHM 2010 era de 0,595. O município de Ouro Verde de Minas se encontrava na posição $788^{\circ}$ de um total de 853 municípios do Estado de Minas Gerais, o que o coloca entre os 73 municípios com os piores índices de desenvolvimento humano no Estado. $O$ valor do rendimento nominal médio mensal dos domicílios particulares permanentes com rendimento domiciliar, por situação do domicílio rural: 868,96 reais e situação urbana: $1.213,24$ reais.

O Produto Interno Bruto (PIB) do ano de 2014 foi de $R \$ 6.537 .000,00$. Com valor adicionado bruto da agropecuária, a preços correntes de $\mathrm{R} \$ 1.980 .000,00$; valor adicionado bruto da indústria, a preços correntes de $R \$ 10.760 .000,00$; valor adicionado bruto dos Serviços, a preços correntes - exclusive administração, saúde e educação públicas e seguridade social de $\mathrm{R} \$ 20.347 .000,00$; com valor adicionado bruto da Administração, saúde e educação públicas e seguridade social, a preços correntes de $\mathrm{R} \$ 39.624 .000,00$; valor adicionado bruto Total, a preços correntes de 
$\mathrm{R} \$ 936.000,00$ e Impostos, líquidos de subsídios, sobre produtos, a preços correntes de $\mathrm{R} \$ 936.000,00$. (IBGE, 2016)

A organização deste estudo constitui um referencial teórico; procedimentos metodológicos; análise dos dados coletados quanto às finanças públicas do município de Ouro Verde de Minas/MG; Apresenta-se como componentes do referencial teórico: a gestão orçamentária municipal, conceitos orçamentários, classificação das receitas e finalidades das despesas e por fim apresenta-se os resultados e a discussão da análise dos dados e as considerações finais.

\section{Gestão orçamentária municipal}

A Constituição Federal de 1988 (CRFB/1988) reconheceu os municípios como entes da federação e assegurou sua autonomia política, administrativa e fiscal. No âmbito da autonomia político-administrativa ficou assegurado a sua administração própria no que se refere aos assuntos de interesses locais, de modo específico, em relação aos tributos e à organização dos serviços públicos (REZENDE, 2006).

Para Souza (2004) as políticas voltadas para a municipalização não foram impulsionadas pela vontade de proporcionar a descentralização administrativa, e sim por uma questão eminentemente política. Nesse contexto, identificam-se alguns fatores que contribuíram para a emancipação de novos municípios.

O primeiro, relativo à arrecadação, com a possibilidade de compartilhamento dos Fundos de Participação entre as unidades novas e antigas; o segundo, de natureza política, já que essas mudanças possibilitariam não apenas o surgimento de lideranças locais, mas também a acomodação de grupos rivais, resultando em um novo formato de repartição do poder político administrativo. Outro aspecto é que a opção pela fragmentação se tornou uma forma de simplificação da gestão por meio de soluções locais (REIS; COSTA; SILVEIRA, 2013, p. 67).

Para Tomio (2002), a garantia de repasse do Fundo de Participação dos Municípios (FPM) foi uma das principais motivações para emancipação de pequenos municípios, pois parecia ser um grande negócio para as pequenas localidades do interior. Esse autor afirmou que a receita própria desses municípios seria incapaz de pagar sequer os cargos políticos criados pela emancipação: prefeitos, vereadores e secretários municipais.

Conforme Reis; Costa e Silveira (2013) o processo de emancipação municipal resultou na criação de grande número de municípios de pequeno porte, com baixa 
capacidade de arrecadação tributária, menores transferências do Imposto sobre Circulação de Mercadorias e Serviços - ICMS e forte dependência do FPM.

Diante o exposto, nota-se que as questões relacionadas às fontes de receitas e destino das despesas de pequenos municípios devem ser postas em pauta.

\subsection{Conceitos Orçamentários}

O direito financeiro e o direito tributário, com base nos estudos do Manual Técnico de Orçamento - MTO (2017); tem por objeto a disciplina jurídica de toda a atividade financeira do Estado e abrange receitas, despesas e créditos públicos.

O Direito Tributário tem por objeto específico a disciplina jurídica de uma das origens da receita pública: o tributo.

As normas básicas referentes ao Direito Financeiro e ao Direto Tributário encontram-se na CF; na Lei no 4.320, de 17 de março de 1964; na Lei no 5.172, de 25 de outubro de 1966 - CTN; na Lei Complementar no 101, de 4 de maio de 2000 LRF; e no Decreto no 93.872, de 24 de dezembro de 1986. Os incisos I e II do art. 24 da CF, a seguir, instituem competência concorrente para legislar sobre o assunto:

Art. 24. Compete à União, aos Estados e ao Distrito Federal legislar concorrentemente sobre:

I - direito tributário, financeiro, penitenciário, econômico e urbanístico;

II - orçamento.

Os princípios orçamentários visam estabelecer regras básicas para conferir racionalidade, eficiência e transparência aos processos de elaboração, execução e controle do orçamento público. Válidos para todos os Poderes e entes federativos União, Estados, Distrito Federal e Municípios, são situados e disciplinados tanto por normas constitucionais e infraconstitucionais quanto pela doutrina.

De acordo com o princípio orçamentário, o orçamento deve ser uno, ou seja, cada ente governamental deve elaborar um único orçamento. Este princípio é mencionado no caput do art. 20 da Lei no 4.320, de 1964, e visa evitar múltiplos orçamentos dentro da mesma pessoa política. Dessa forma, todas as receitas previstas e despesas fixadas, em cada exercício financeiro, devem integrar um único documento legal dentro de cada nível federativo: LOA- Lei Orçamentária Anual, onde cada ente da Federação elaborará a sua própria LOA. MTO (2017) 
A universalidade, segundo este princípio, na LOA de cada ente federado deverá conter todas as receitas e as despesas de todos os Poderes, órgãos, entidades, fundos e fundações instituídas e mantidas pelo poder público. Este princípio é mencionado no caput do art. 20 da Lei no 4.320, de 1964, recepcionado e normatizado pelo $§ 50$ do art. 165 da CF.

A anualidade ou periodicidade do exercício financeiro é o período de tempo ao qual se referem a previsão das receitas e a fixação das despesas registradas na LOA. Este princípio é mencionado no caput do art. 20 da Lei no 4.320, de 1964. Segundo o art. 34 dessa lei, o exercício financeiro coincidirá com o ano civil $\left(1^{\circ}\right.$ de janeiro a 31 de dezembro).

O princípio da exclusividade está previsto no $§ 80$ do art. 165 da CF, estabelece que a LOA não conterá dispositivo estranho à previsão da receita e à fixação da despesa. Ressalvam-se dessa proibição a autorização para abertura de créditos suplementares e a contratação de operações de crédito, ainda que por Antecipação de Receitas Orçamentárias - ARO, nos termos da lei.

O orçamento bruto é um princípio previsto no art. 60 da Lei no 4.320 , de 1964, preconiza o registro das receitas e despesas na LOA pelo valor total e bruto, vedadas quaisquer deduções.

A não vinculação da receita de impostos, está estabelecida pelo inciso IV do art. 167 da CF, este princípio veda a vinculação da receita de impostos a órgão, fundo ou despesa, salvo exceções estabelecidas pela própria CF:

\footnotetext{
Art. 167. São vedados:

[...]

IV - a vinculação de receita de impostos a órgão, fundo ou despesa, ressalvadas a repartição do produto da arrecadação dos impostos a que se referem os arts. 158 e 159, a destinação de recursos para as ações e serviços públicos de saúde, para manutenção e desenvolvimento do ensino e para realização de atividades da administração tributária, como determinado, respectivamente, pelos arts. 198, §2으, 212 e 37, XXII, e a prestação de garantias às operações de crédito por antecipação de receita, previstas no art. 165 , $\S 8^{\circ}$, bem como o disposto no $\S 4^{\circ}$ deste artigo; (Redação dada pela Emenda Constitucional no 42, de 19.12.2003); [...]

$\S 4^{\circ}$ É permitida a vinculação de receitas próprias geradas pelos impostos a que se referem os arts. 155 e 156, e dos recursos de que tratam os arts. 157, 158 e 159, I, a e b, e II, para a prestação de garantia ou contra garantia à União e para pagamento de débitos para com esta. (Incluído pela Emenda Constitucional no 3, de 1993). MTO (2017)
}

\subsection{Receita Públicas}


O orçamento é instrumento de planejamento de qualquer entidade, seja pública ou privada, e representa o fluxo previsto dos ingressos e das aplicações de recursos em determinado período. A matéria pertinente à receita é disciplinada, em linhas gerais, pelos arts. $3^{\circ}, 9^{\circ}, 11^{\circ}, 35^{\circ}$ e $57^{\circ}$ da Lei no 4.320 , de 1964 . Em sentido amplo, receitas públicas são ingressos de recursos financeiros nos cofres do Estado, que se desdobram em receitas orçamentárias, quando representam disponibilidades de recursos financeiros para o erário, e ingressos extra orçamentários, quando representam apenas entradas compensatórias. Em sentido estrito, são públicas apenas as receitas orçamentárias. MTO (2017)

Os ingressos extra orçamentários, são recursos financeiros que apresentam caráter temporário e não integram a LOA. O Estado é mero depositário desses recursos, que constituem passivos exigíveis e cujas restituições não se sujeitam à autorização legislativa. Exemplos: Depósitos em Caução, Fianças, Operações de Crédito por Antecipação de Receitas Orçamentárias - ARO, emissão de moeda e outras entradas compensatórias no ativo e passivo financeiros. MTO (2017)

As receitas orçamentárias são disponibilidades de recursos financeiros que ingressam durante o exercício e constituem elemento novo para o patrimônio público. Instrumento por meio do qual se viabiliza a execução das políticas públicas, a receita orçamentária é fonte de recursos utilizada pelo Estado em programas e ações cuja finalidade precípua é atender às necessidades públicas e demandas da sociedade. Essas receitas pertencem ao Estado, integram o patrimônio do Poder Público, aumentam-lhe o saldo financeiro e, via de regra, por força do princípio da universalidade, estão previstas na LOA. MTO (2017)

Nesse contexto, embora haja obrigatoriedade de a LOA registrar a previsão de arrecadação das receitas, a mera ausência formal desse registro não lhes retira o caráter orçamentário, haja vista o art. 57 da Lei no 4.320, de 1964, classificar como receita orçamentária toda receita arrecadada que represente ingresso financeiro orçamentário, inclusive a proveniente de operações de crédito. MTO (2017)

Segundo descrito no Manual Técnico de Orçamento - MTO (2017), A classificação da receita orçamentária, a exemplo do que ocorre na despesa, é de utilização obrigatória por todos os entes da Federação, sendo facultado o seu desdobramento para atendimento das respectivas necessidades. Sobre o assunto, as receitas orçamentárias são classificadas segundo os seguintes critérios: 
1. natureza de receita;

2. indicador de resultado primário;

3. fonte/destinação de recursos; e

4. esfera orçamentária.

\subsection{Despesa Públicas}

A estrutura da programação orçamentária, a compreensão do orçamento exige o conhecimento de sua estrutura e sua organização, implementadas por meio de um sistema de classificação estruturado.

Esse sistema tem o propósito de atender às exigências de informação demandadas por todos os interessados nas questões de finanças públicas, como os poderes públicos, as organizações públicas e privadas e a sociedade em geral. Na estrutura atual do orçamento público, as programações orçamentárias estão organizadas em programas de trabalho, que contêm informações qualitativas e quantitativas, sejam físicas ou financeiras. MTO (2017)

A programação qualitativa define qualitativamente a programação orçamentária, deve responder, de maneira clara e objetiva, às perguntas clássicas que caracterizam o ato de orçar, sendo, do ponto de vista operacional, composto dos seguintes blocos de informação: classificação por esfera, classificação institucional, classificação funcional, estrutura programática e principais informações do Programa e da Ação. MTO (2017)

A programação orçamentária quantitativa tem duas dimensões: a física e a financeira. A dimensão física define a quantidade de bens e serviços a serem entregues. A dimensão financeira estima o montante necessário para o desenvolvimento da ação orçamentária. MTO (2017)7

A classificação da despesa por esfera orçamentária está na LOA, a esfera tem por finalidade identificar se a despesa pertence ao Orçamento Fiscal (F), da Seguridade Social (S) ou de Investimento das Empresas Estatais (I), conforme disposto no $\S 5^{\circ}$ do art. 165 da CF. Na LOA, o classificador de esfera é identificado com as letras "F", "S" ou "I", na base de dados do SIOP. MTO (2017)

A classificação funcional é formada por funções e subfunções e busca responder basicamente à indagação "em que áreas de despesa a ação 
governamental será realizada?". Cada atividade, projeto e operação especial identificará a função e a subfunção às quais se vinculam.

A atual classificação funcional foi instituída pela Portaria no 42, de 14 de abril de 1999, do então Ministério do Orçamento e Gestão (MOG), e é composta de um rol de funções e subfunções prefixadas, que servem como agregador dos gastos públicos por área de ação governamental nos três níveis de Governo. Trata-se de uma classificação independente dos programas e de aplicação comum e obrigatória, no âmbito dos Municípios, dos Estados, do Distrito Federal e da União, o que permite a consolidação nacional dos gastos do setor público. MTO (2017)

Toda ação do Governo está estruturada em programas orientados para a realização dos objetivos estratégicos definidos para o período do PPA, ou seja, quatro anos.

Para classificar uma despesa quanto à sua natureza deve-se considerar a categoria econômica, o grupo a que pertence, a modalidade da aplicação e o elemento. A modalidade de aplicação destina-se a indicar se os recursos serão aplicados diretamente pela unidade detentora do crédito orçamentário, ou transferidos, ainda que na forma de descentralização, a outras esferas de governo, órgãos ou entidades. MTO (2017)

\section{Procedimentos metodológicos}

Aqui se trata da abordagem metodológica, caracterizando o tipo de pesquisa quanto aos fins e aos meios, apresentando o que constitui a unidade de análise, e definindo os instrumentos de coleta de dados, as variáveis analisadas e qual a técnica de análise de resultados.

Para Richardson (1989, p. 29) "(...) método em pesquisa significa a escolha de procedimentos sistemáticos para a descrição e explicação de fenômenos". Desta forma, todo trabalho de pesquisa deve ser planejado e executado de acordo com as normas que acompanham cada método. As duas estratégias de pesquisa, quanto à aplicabilidade podem ser chamadas de abordagem qualitativa e abordagem quantitativa, utilizando-se uma classificação bastante ampla.

Nesta pesquisa, foi utilizada a abordagem quantitativa, visando identificar qual o perfil orçamentário do município de Ouro Verde de Minas - MG no período de 2000 a 2015. Segundo Zanella (2009) a pesquisa quantitativa caracteriza-se pelo uso de 
instrumentos estatísticos e tem como finalidade medir as relações entre as variáveis, apresentando uma preocupação com a representatividade numérica.

O município de Ouro Verde de Minas - MG foi escolhido como objeto de estudo, caracterizado com um estudo de caso, que Yin (2001, p.32) define como "investigação empírica que investiga um fenômeno contemporâneo dentro do seu contexto da vida real, especialmente quando os limites entre fenômeno e contexto não estão claramente definidos". Este município tem uma população estimada de 6.016 habitantes. Com PIB per capita de R\$6.607,95 (IBGE, 2014). Percentual as receitas oriundas de fontes externas (2015) perfazendo 96,7\%. De acordo o ranking do Índice de Desenvolvimento Humano Municipal - IDHM 2010 era de 0,595.

Quanto aos procedimentos a pesquisa se classifica como bibliográfica, pois utilizou-se livros e artigos científicos com base teórica da análise e quanto aos dados utilizados, foram dados secundários coletados nas bases de dados da STN (Secretaria do Tesouro Nacional), a FINBRA (Finanças do Brasil). Os dados coletados correspondem às receitas e despesas pagas.

Tomou-se como série histórica os dados de 2000 a 2015, ressalvando que os valores foram atualizados pelo IGP-DI/FGV (Índice Geral de Preços Disponibilidade Interna), tendo por base o ano 2016 para ajustar os preços correntes. Após coletados e deflacionados os dados foram analisados quantitativamente para identificar a composição orçamentária do município, verificando às principais classificações de receita e despesas, apresentando os dados em gráficos para facilitar a análise.

\section{4 . Resultados e discussão dos dados coletados}

No contexto de finanças públicas e orçamento público, que esse estudo traz como problematização: Qual o perfil orçamentário (principais fontes de receita e destino de despesas) do município de Ouro verde de Minas/MG no período de 2000 a 2016? Para alcançar a proposta, identificou-se a composição orçamentária do município quanto às principais fontes de receita e despesas em termos da classificação por finalidade do gasto e por natureza do gasto; e buscou-se avaliar a distribuição orçamentária, diante o que estabelece os limites previstos na legislação.

O município de Ouro verde de Minas/MG expressa o perfil de muitos municípios brasileiros, com pequeno número de habitantes, apresentando um 
quadro de grande dependência financeira em relação aos entes federados superiores por uma arrecadação própria insuficiente para atender as demandas da população. A análise dos Resultados obtidos através dos dados coletados apresenta primeiramente as análises quanto a variação da população local.

\section{1. - Gráfico ํô1 - Evolução a população Munic. Ouro Verde de Minas}

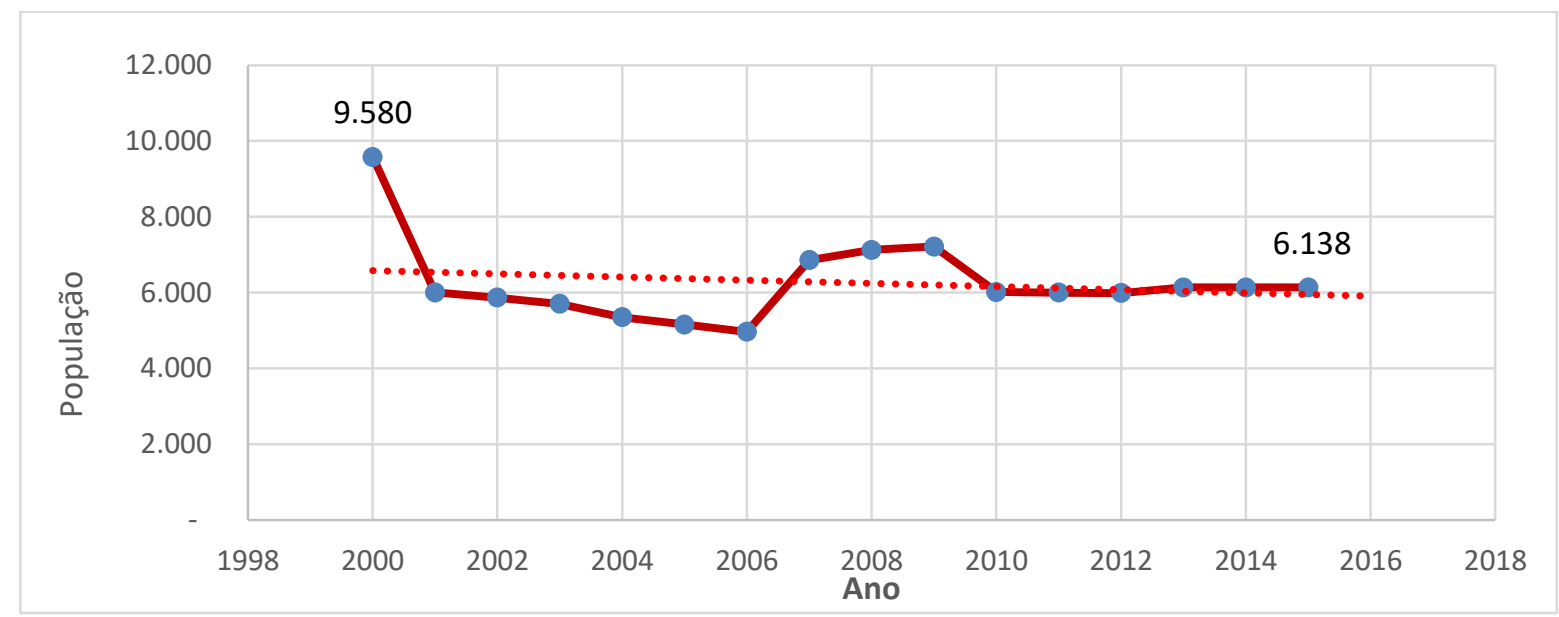

Fonte: Elaborado pelos autores -Dados coletados site - www.tesouro.fazenda.gov.br/finbra-financasmunicipais.

Observa-se no gráfico № 1, uma tendência a diminuição da população do Município de Ouro verde de Minas. Por volta do ano 2000 a população do município, conforme dados do IBGE, era de 9.580 pessoas, em 2016 a população local está em torno de 6.138 habitantes. Um decréscimo de aproximadamente $36 \%$, porem, as despesas e receitas não apresentam a mesma variação. As Receitas Orçamentárias em comparação com as Despesas Orçamentárias conforme se observa no gráfico №2, abaixo, no período de 2000 a 2015. As receitas orçamentárias e despesas orçamentárias evoluíram e tendem a manter um equilíbrio entre se. A partir de 2008 pode-se observar a tendência de que as receitas passem a ser superiores as despesas, tendendo a respeitar o proposto pela Lei de Responsabilidade Fiscal (LRF), que determina que as despesas não deverão ultrapassar as receitas.Os principais pontos da Lei de Responsabilidade Fiscal (LRF) - Lei Complementar 101/2000, são: estabelece limites para despesas com pessoal e para dívida pública; e determina que sejam criadas metas para controlar receitas e despesas. 
4.2- Gráfico nำ- Receitas Orçamentárias e Despesas Orçamentárias de 2000 a 2015.

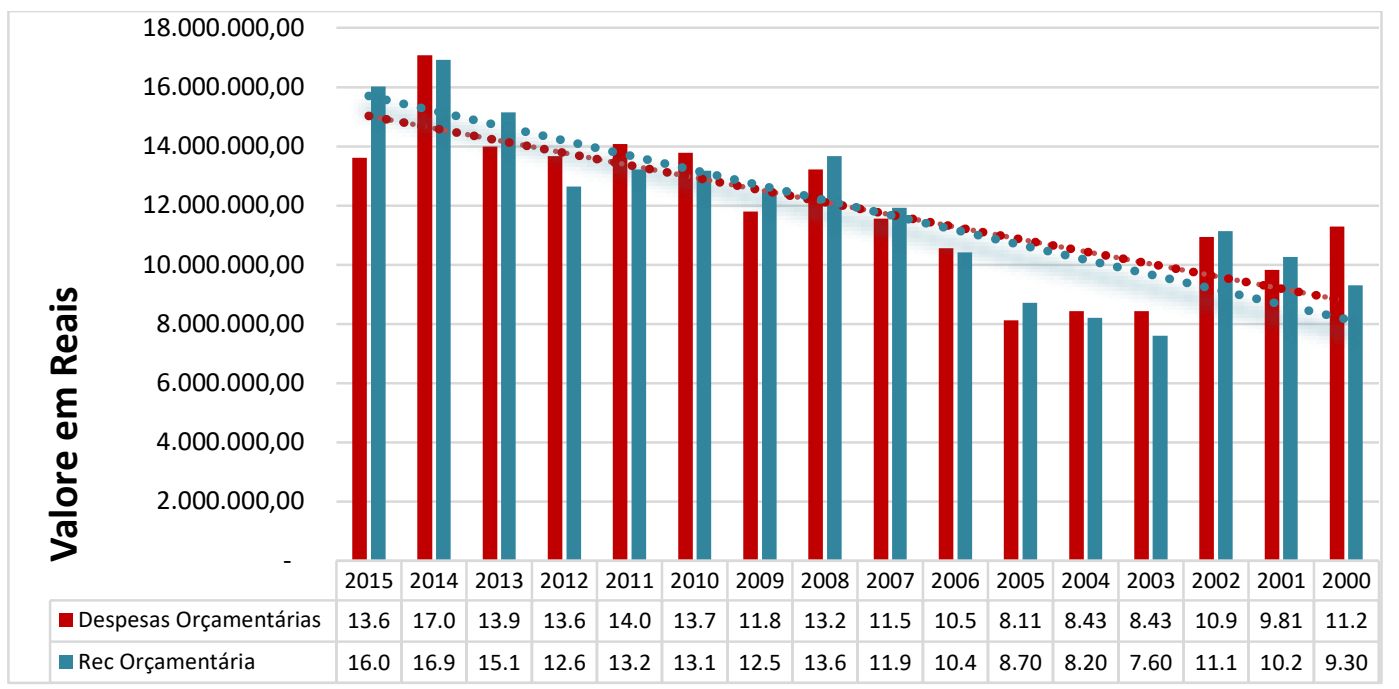

Fonte:Elaborado pelos autores -Dados coletados site - www.tesouro.fazenda.gov.br/finbra-financasmunicipais.

$\mathrm{Na}$ classificação quanto à origem das receitas, tem-se as Receitas Correntes e Receitas de Capital, como mostra o gráfico 3, as Receitas Correntes representam a maior parcela das Receitas Orçamentárias, 93,75\%; as Receitas de Capital correspondem em 6,25\% no ano de 2015. Observa-se uma tendência de diminuição da participação das Receitas de Capital no bojo das receitas do município.

4.3- Gráfico no3- Evolução da Receitas Corrente e Receita de Capital de 2000 a 2015.

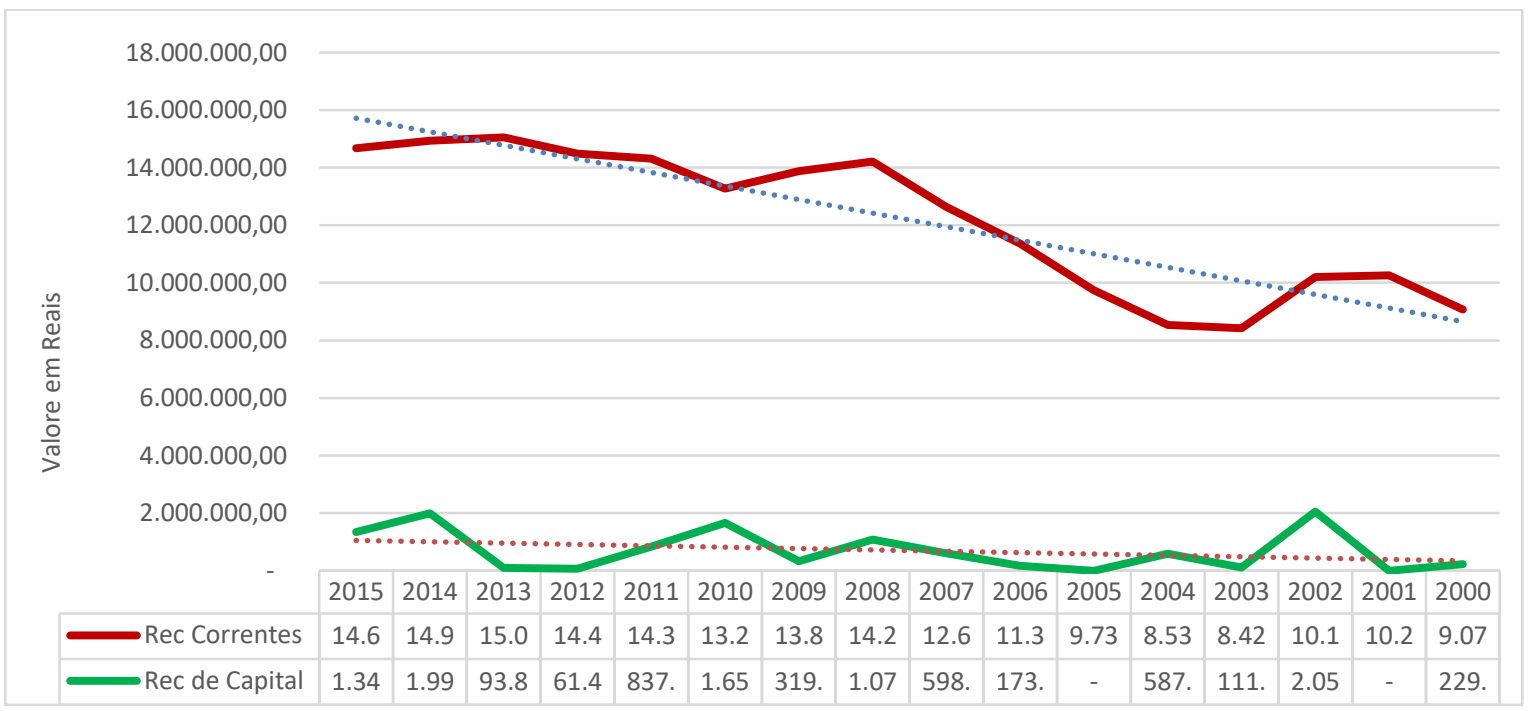

Fonte: Elaborado pelos autores -Dados coletados site - www.tesouro.fazenda.gov.br/finbra-financasmunicipais. 
As fontes de receitas do Município de Ouro Verde e Minas no período de 2000 a 2015 são em sua maioria recursos repassados pela União e Estado. A arrecadação do município é baixa em relação as suas despesas. Demonstrando forte dependência dos repasses instituídos em lei, conforme notado no gráfico no 4 .

Quanto a Classificação por captação de recursos como visto as receitas, podem ser de Transferência ou Receitas Próprias, analisando o perfil de arrecadação do Município de Ouro Verde e Minas no período de 2000 a 2015, verifica-se que as Receitas Próprias representam em média 2\%, em 2015, não são suficientes para atender as demandas da população, situação comum entre municípios pequenos que dependem das Transferências Intergovernamentais que respondem por $98 \%$ das receitas do referido município.

Há uma tendência de que as receitas próprias se mantenham neste nível, enquanto as transferências governamentais sejam incrementadas, como observado no gráfico abaixo.

\section{4- Gráfico nº- Evolução da Receitas Intergovernamentais e Receita Tributária.}

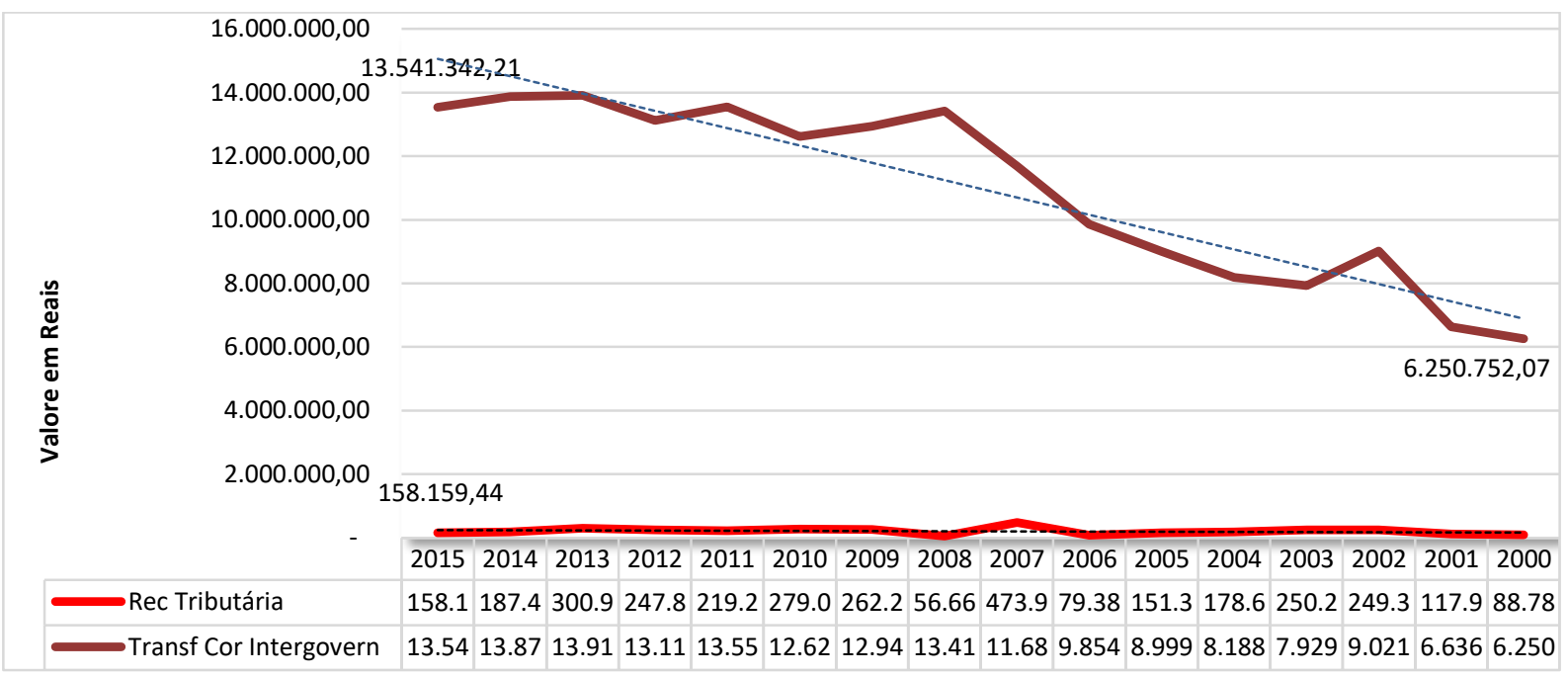

Fonte: Elaborado pelos autores -Dados coletados site - www.tesouro.fazenda.gov.br/finbra-financasmunicipais.

Analisando as Transferências Intergovernamentais, observa-se conforme mostra o Gráfico 5, um crescimento do valor das transferências no decorrer dos anos sendo que a maior parcela de transferências recebidas pelo Município de Ouro Verde e Minas no período de 2000 a 2015, são oriundas da União, havendo também transferências do Estado. 


\section{5- Gráfico n5- Evolução da Transferência Receitas Intergovernamentais.}

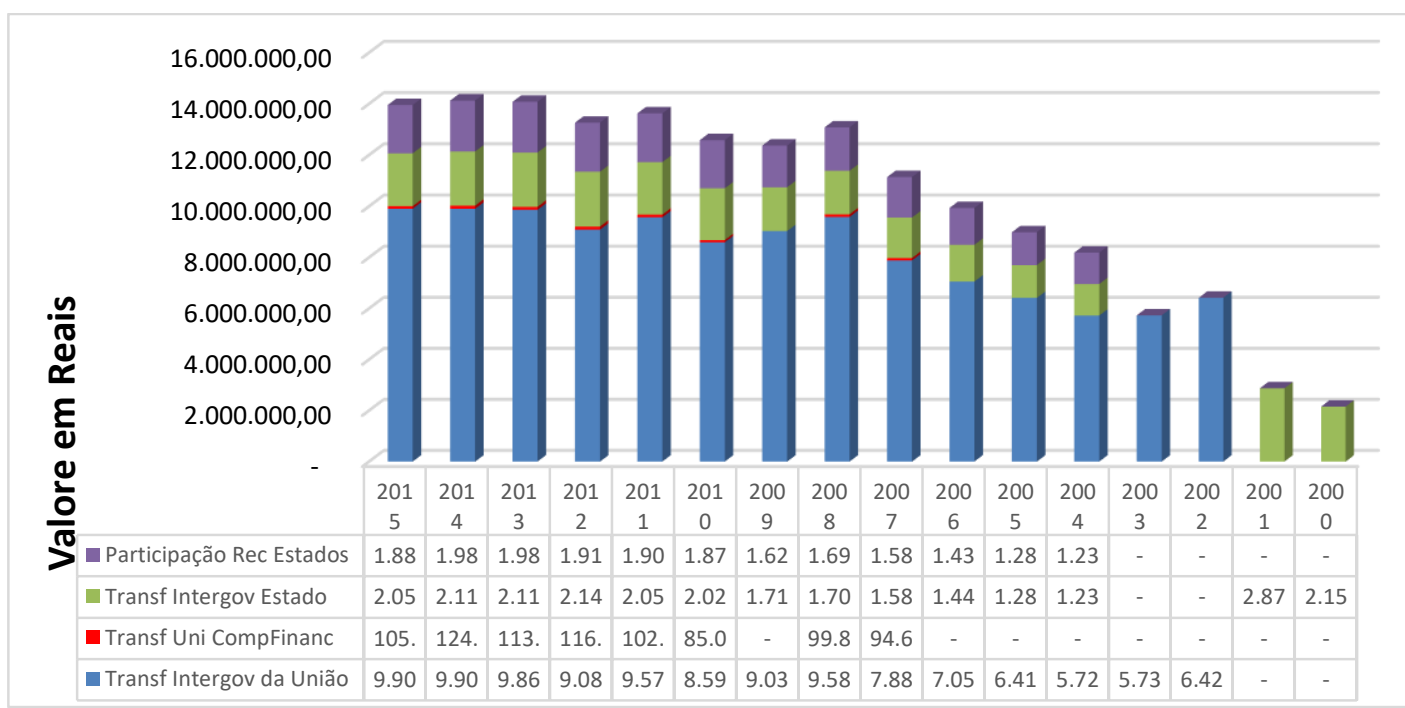

Fonte: Elaborado pelos autores -Dados coletados site - www.tesouro.fazenda.gov.br/finbra-financasmunicipais.

As Transferências da União representam a maior parcela de transferências recebidas pelo município, destacando a Cota do Fundo de Participação dos Municípios repassada pela União que representa em torno de $60 \%$ do total de receitas arrecadas pelo município, seguido pela representatividade do Cotas do ICMS, com repasse em torno de uma média de 13\%, o FUNDEB com repasse em torno de uma média de 12\%. As demais transferências têm baixa representatividade.

\section{6- Gráfico no6- Evolução da Transferência de outras Receitas Intergovernamentais}

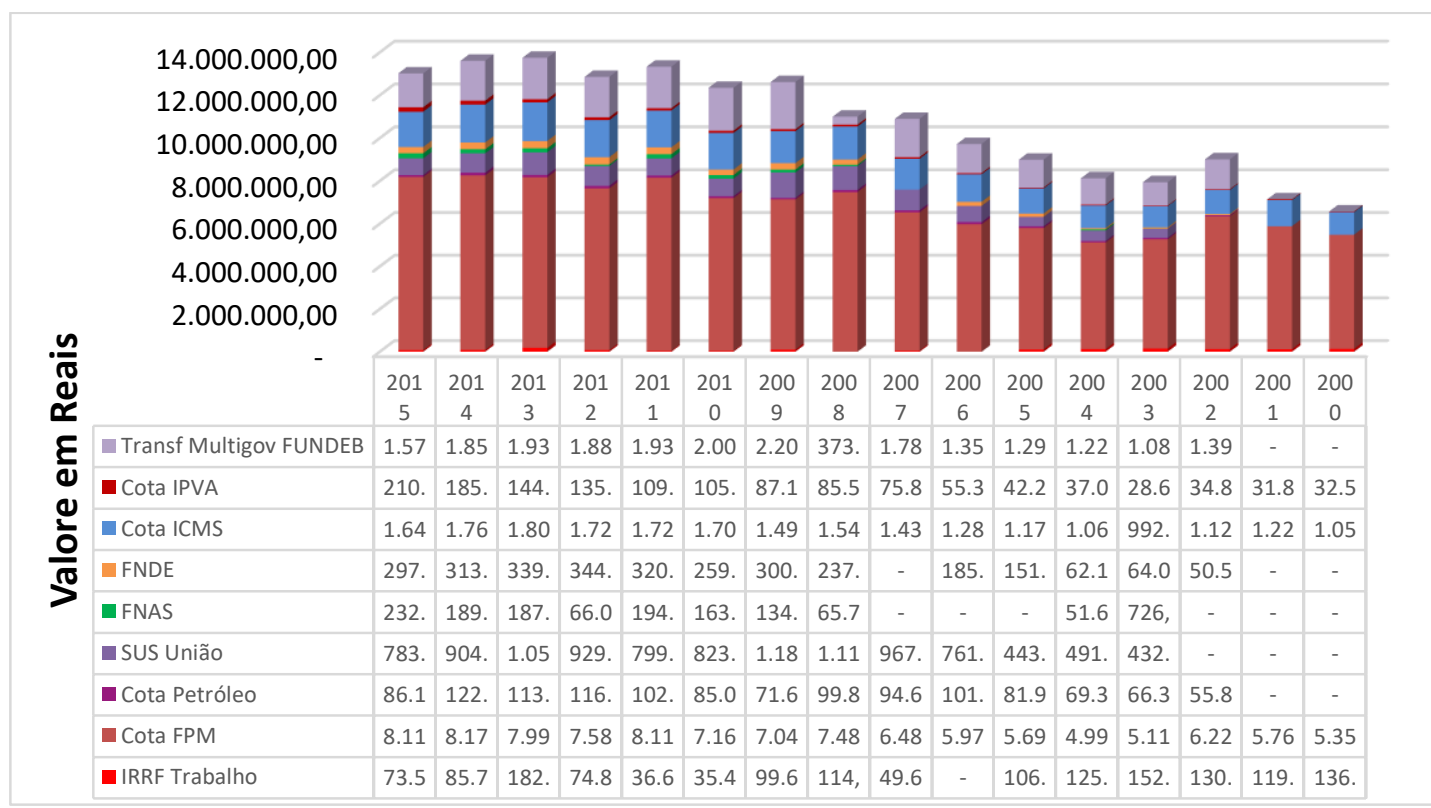

Fonte: Elaborado pelos autores -Dados coletados site - www.tesouro.fazenda.gov.br/finbra-financasmunicipais. 
Dentre os tributos arrecadados pelo município os que mais impactam nas receitas próprias são os impostos, como observado no gráfico $\mathrm{n}^{\circ} 7$, sendo que no município de Ouro Verde de Minas os de maior representatividade são o ISSQN e o IRRF Trabalho, o que reforça a caracterização do município, que o maior valor acrescido do PIB vem da Prestação de Serviços. O IPTU tem parcela mínima nas receitas próprias. No ano de 2007 verifica-se um aumento elevado na arrecadação do ISSQN, trata-se de um fato isolado, que não foi possível apurar a razão.

4.7 - Gráfico oำ- Evolução da Receitas com os principais impostos.

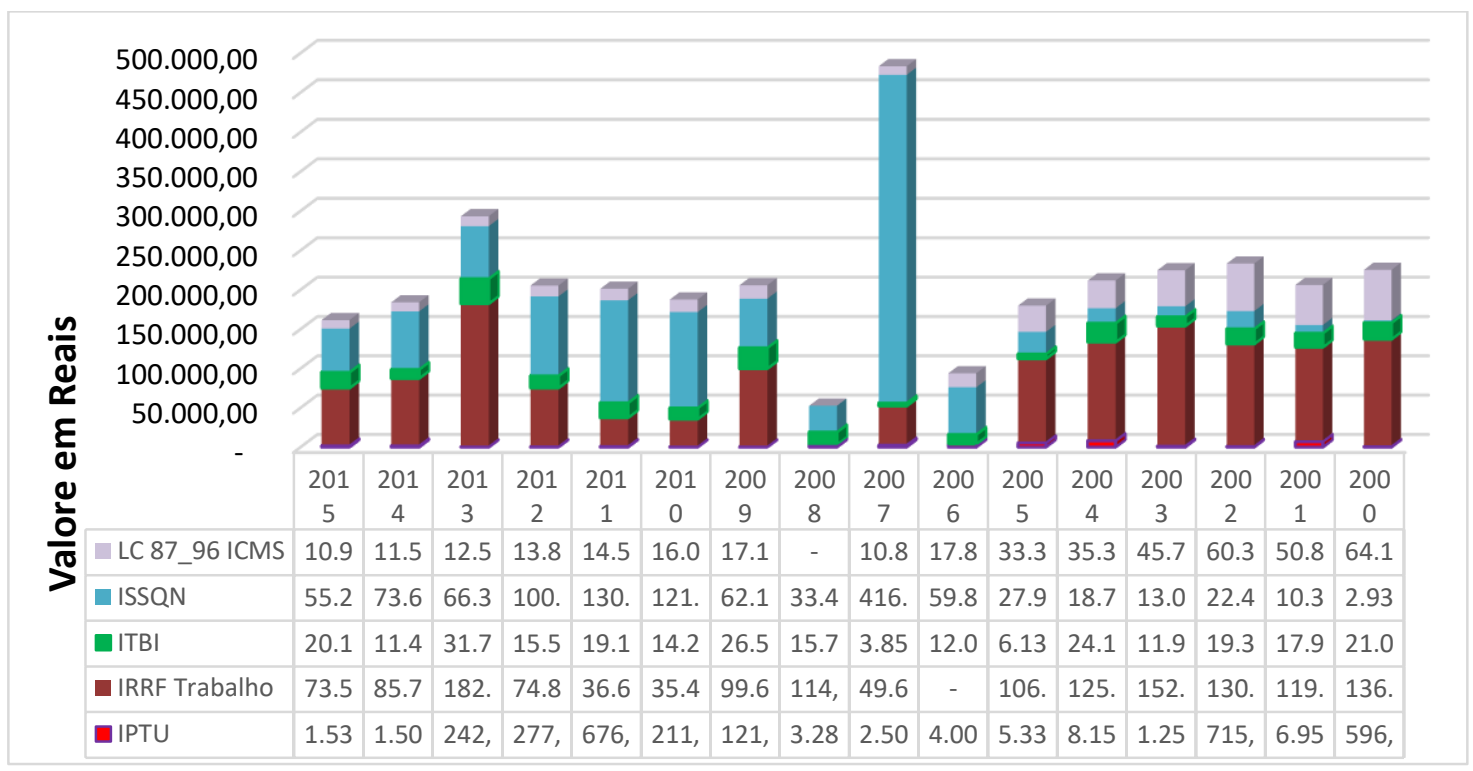

Fonte: Elaborado pelos autores -Dados coletados site - www.tesouro.fazenda.gov.br/finbra-financasmunicipais.

Com estas analise sobre as Receitas Orçamentárias do município de Ouro Verde de Minas no período de 2000 a 2015, observa-se um crescimento das Receitas Orçamentárias, para o atendimento das demandas da população. Dessas Receitas as maiores representatividades são das Receitas Correntes, não havendo grandes variações das Receitas de Capital. Na classificação quanto à Captação de Receitas verifica-se uma grande dependência do Município de Recursos externos, sendo os recursos de arrecadação própria insuficiente para suprir as necessidades da população. As principais transferências recebidas pelo município são a Cota do FPM oriunda da União e a Cota do ICMS remetida pelo Estado.

A análise do perfil orçamentário do município não se baseia somente nas receitas, sendo necessário compreender também as Despesas para que esse perfil se complete. Quanto a Despesas Orçamentárias do município pode-se verificar que 
assim como as Receitas Orçamentárias houve um crescimento no decorrer dos anos, como mostra a linha de tendência traçada no Gráfico 8 abaixo. Na análise horizontal constatou-se que as Despesas Orçamentárias elevaram em torno de $28 \%$ do ano de 2000 a 2015, e tendem a elevaram nos próximos anos, conforme observado na linha de tendência do gráfico abaixo.

\section{8 - Gráfico ㄲo8- Evolução da Despesas Orçamentarias.}

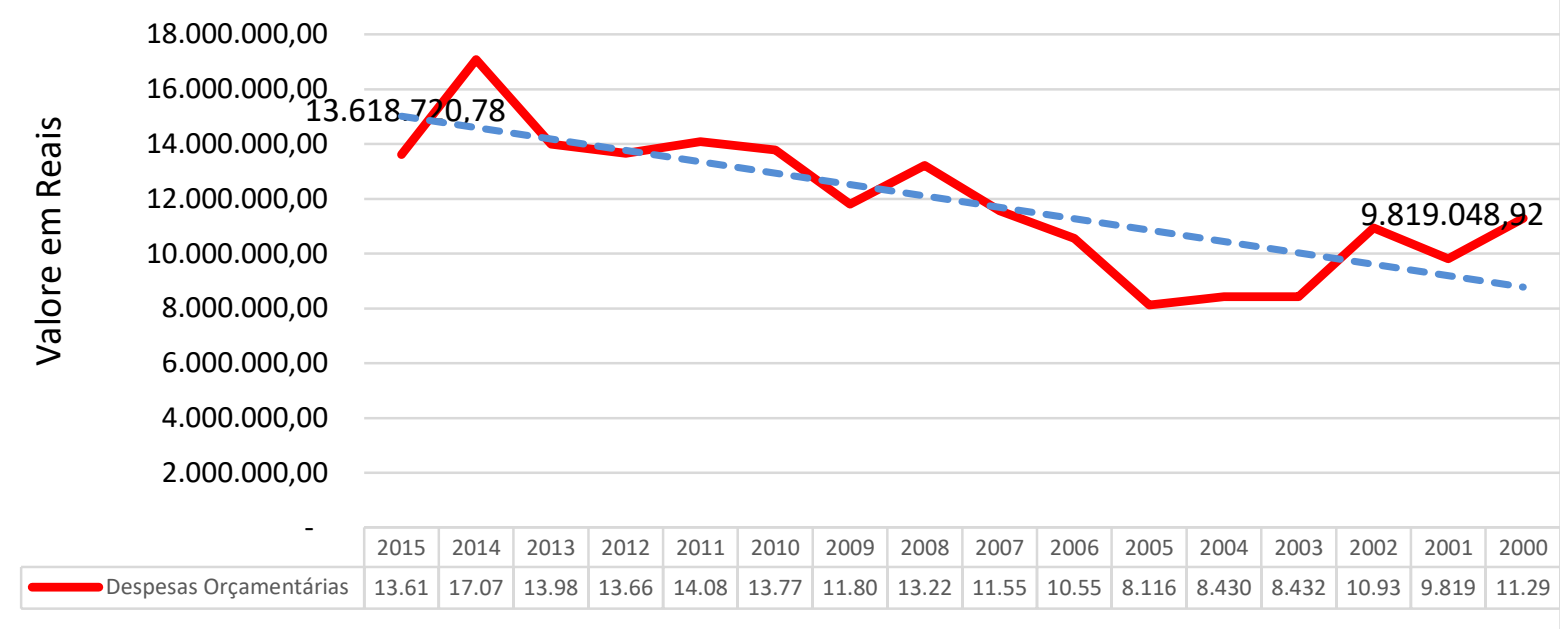

Fonte: Elaborado pelos autores -Dados coletados site - www.tesouro.fazenda.gov.br/finbra-financasmunicipais.

$\mathrm{Na}$ classificação quanto á natureza das despesas pode-se destacar as Despesas Correntes e as Despesas de Capital, no município de Ouro Verde de Minas há uma concentração das despesas na categoria corrente havendo um crescimento ao logo dos anos estudados.

4.9 - Gráfico nำ - Evolução da Despesas Correntes x Despesas de Capital.

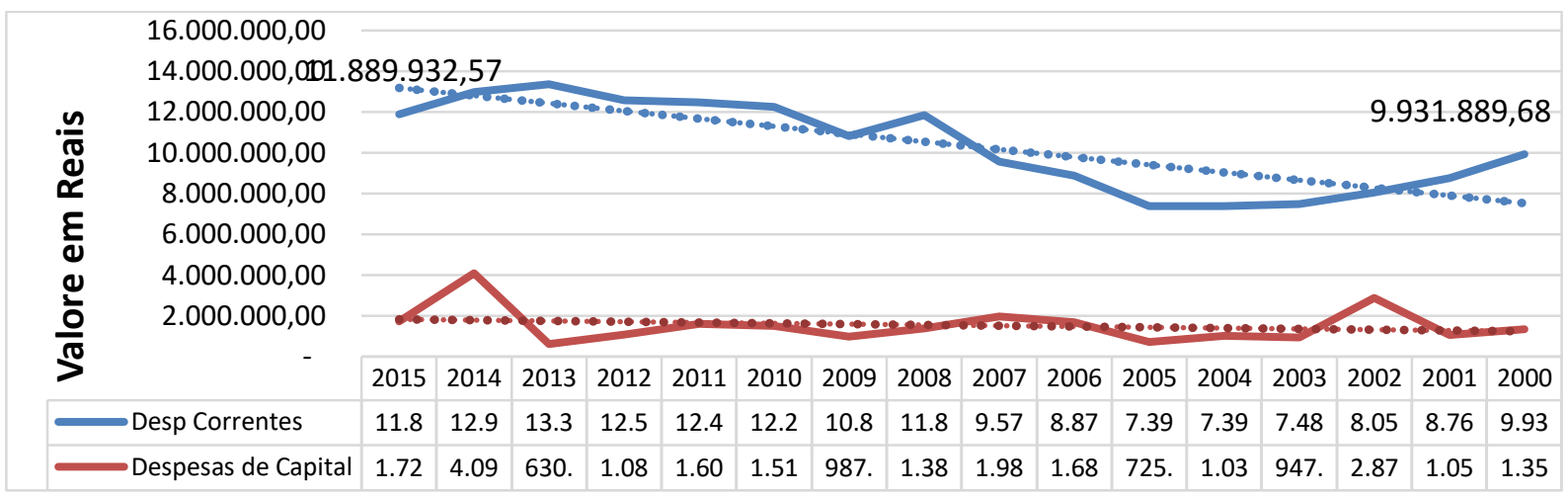

Fonte: Elaborado pelos autores -Dados coletados site - www.tesouro.fazenda.gov.br/finbra-financasmunicipais. 
No entanto, as Despesas de Capital tiveram um leve crescimento no decorrer dos anos também, como visto no Gráfico 9, representando um crescimento de $21 \%$ de 2000 em comparação a 2015, tendo pico no ano de 2014 ocasionando uma pequena queda das Despesas Correntes do anoseguinte.

Os gastos no decorrer dos anos em relação as Receitas Correntes Liquidas, considerando os limites estabelecidos na LRF quanto aos limites de gastos com Pessoal e as despesas de Educação e Cultura e as despesas com Saúde e Saneamento, não se encontram disponíveis para os anos de 2000 a 2006; 2014 a 2016 para analise, dificultando assim uma avaliação mais detalhada, conforme podemos observar no quadro №1, abaixo:

\begin{tabular}{|c|c|c|c|}
\hline \multicolumn{5}{|c|}{ Porcentagem de Gastos em Relação à Receita Corrente Líquida (2000 a } \\
\hline Ano & Saúde & Educação & Gasto com Pessoal \\
\hline 2000 & & & \\
\hline 2001 & & & \\
\hline 2002 & & & \\
\hline 2003 & & & \\
\hline 2004 & & & \\
\hline 2005 & & $15,21 \%$ & $54,32 \%$ \\
\hline 2006 & & $29,87 \%$ & $54,85 \%$ \\
\hline 2007 & $17,36 \%$ & $28,05 \%$ & $58,61 \%$ \\
\hline 2008 & $22,79 \%$ & $27,80 \%$ & $51,04 \%$ \\
\hline 2009 & $15,95 \%$ & $28,82 \%$ & $55,41 \%$ \\
\hline 2010 & $15,97 \%$ & $28,29 \%$ & $58,63 \%$ \\
\hline 2011 & $15,56 \%$ & $26,37 \%$ & \\
\hline 2012 & $15,69 \%$ & & Pessoal \\
\hline 2013 & $19,78 \%$ & & $53,89 \%$ \\
\hline 2014 & & & \\
\hline 2015 & & $26,34 \%$ & \\
\hline 2016 & & & \\
\hline & Saúde & & \\
\hline Média & $\mathbf{1 7 , 5 9 \%}$ & & \\
\hline
\end{tabular}

Fonte: Elaborado pelos autores

Dados coletados site - http://fiscalizandocomtce.tce.mg.gov.br/Paginas/Indices_Constitucionais_e_Legais

Saúde: Fundamento constitucional: Atr. 77 , Inc. III do ADCT, com redação dada pelo art. $7^{\circ}$ da E $\bar{C}$ n. 29/00: Mínimo de 15\% da receita de impostos e transferências.

Educação: Fundamento constitucional: Atr. 212 da CR/88: Mínimo de 25\% da receita de impostos e transferências.

D. Pessoal: Fundamento constitucional: Art. 19, inc III e art. 20, inc III, alíneas a e b da Lei Complementar n.101/00: Máximo de $60 \%$ da Receita Corrente Líquida, sendo 6\% para o Poder Legislativo e 54\% para o Poder Executivo.

Conforme observa-se: Porcentagem de Gastos em Relação à Receita Corrente Líquida (2000 a 2016), infere-se que para o item Saúde foram atendidos os índices mínimos de acordo com a LRF, que pauta em 15\% da receita de impostos e transferências. Quanto as aplicações que deveriam serem destinadas a Educação observa-se que em 2007 o índice mínimo de 25\% não foi atendido, ficando em 
$15,21 \%$, ficando abaixo do previsto em torno de 9,79\%. Para os Gastos com Pessoal os índices previstos foram atendidos conforme estabelecido no Fundamento constitucional: Art. 19, inc III e art. 20, inc III, alíneas a e b da Lei Complementar n.101/00, é de no máximo de $60 \%$ da Receita Corrente Líquida, sendo 6\% para o Poder Legislativo e 54\% para o Poder Executivo.

\section{Considerações finais}

O estudo de avaliação das receitas e despesas do município de Ouro Verde de Minas, no período de 2000 a 2015, foi feito com base em estudos teóricos e dados providos pelo Tesouro nacional, no site - www.tesouro.fazenda.gov.br/finbrafinancas-municipais e do TCE - Tribunal de Contas Estado de MG, no site: http://fiscalizandocomtce.tce.mg.gov.br.

Observa-se que as contas dos municípios são apresentadas anualmente e sofrem variações na sua classificação, dificultando a correta coleta de dados. Para análise das contas públicas do Município de Ouro Verde de Minas necessita-se de conhecimentos complexos sobre administração orçamentária pública. Principalmente a luz das leis vigentes, para isso analisou-se os dados do período identificando o comportamento temporal das receitas e despesas ressaltando as que têm maior representatividade nas classificações de captação e origem de receitas, natureza e finalidade das despesas.

No contexto de finanças públicas e orçamento público, o perfil orçamentário, com suas principais fontes de receita e destino de despesas, do município de Ouro verde de Minas, no período de 2000 a 2015. Sendo um município de pequeno porte e predominantemente rural, tem uma arrecadação própria insuficiente para atender as demandas da população, dependendo assim, principalmente das Transferências Intergovernamentais para atender aos gastos públicos.

Observa-se no gráfico ํำ1, apresentados neste estudo que: as Receitas Orçamentárias em comparação com as Despesas Orçamentarias do Município de Ouro Verde e Minas no período de 2000 a 2015, tendem a manter um equilíbrio, as despesas orçamentárias apresentam-se superiores as receitas orçamentarias. Demonstrando que não foram atendidas as leis vigentes, como a Lei de Responsabilidade Fiscal (LRF) - Lei Complementar n.101/00, que determina que sejam criadas metas para controlar receitas e despesas de cada ente da federação. 
As despesas estudadas do Município de Ouro Verde de Minas demonstram uma evolução crescente, entretanto nas classificações das despesas não foi possível observar entre os anos de 2000 a 2006 e 2013 a 2016; os gastos com educação, saneamento básico e saúde, conforme observado no quadro $n^{0}$ 1, conforme previsto na Lei de responsabilidade fiscal-LRF.

Pelo estudo proposto pode-se aferir que as leis vigentes, que tratam das vinculações de receitas previstas, não foram atendidas, quanto as aplicações que deveriam serem destinadas a Educação em 2007. O índice mínimo de $25 \%$ não foi atendido, ficando em $15,21 \%$, abaixo dos $25 \%$ em torno de $39,16 \%$.

Ressalta no período de 2000 a 2016 um decréscimo populacional, que não foi possível avaliar em virtude da falta de informações disponíveis. Em contrapartida observa-se um crescimento das receitas e despesas. Acredita-se que no futuro se possa estudar este fenômeno que no momento não é objeto deste estudo.

Finalmente, ao analisar os dados do período entre os anos 2000 e 2015 as despesas orçamentárias e receitas orçamentárias executadas não são passiveis de uma comparação entre o que foi previsto e o que foi executado em sua totalidade. Para que se aplique corretamente a legislação, faz-se necessário uma maior fiscalização e aplicação das correções previstas em lei para todos os entes da federação.

\section{Referências}

ACKOFF, Russel L. Planejamento Empresarial. Rio de janeiro, Livros Técnicos e Científicos, Editora S.A., 1975, 126 p.

Brasil, Constituição da República Deferativa do Brasil (1988). Disponível em :http://www.planalto.gov.br/ccivil03/constuição. Acesso em: 5 de Abril de 2017.

,Lei 4.320, de 17 de Março de 1964. Disponivel:

http://www.planalto.gov.br/ccivil_03/leis/L4320.htm, Acesso: 16/04/2017

, Lei Complementar número 101, de 04 de Maio de 2.000. Disponivel: www.planalto.gov.br/ccivil_03/leis/LCP/Lcp101.htm, Acesso: 15/04/2017

,Lei № 5.172, de 25 de outubro de 1966. Disponível:

www.planalto.gov.br/ccivil_03/leis/L5172.htm, Acesso: 15/04/2017

, Decreto no 93.872, de 24 de dezembro de 1986. Disponível:

www.planalto.gov.br/ccivil_03/decreto/d93872.htm, Acesso: 15/04/2017 
DIAS, Fernando A. C.; TAVARES, José F. C. Impacto da desvinculação de receitas da União no orçamento federal e em gastos sociais. Cadernos Aslegis, Brasília, v. 3, n. 9, p. 51-67, 1999.

DIAS, Fernando A. C. Desvinculação de receitas da União, ainda necessária? Núcleo de Estudos e Pesquisas do Senado - Textos para discussão, n. 103, p. 125, 2011.

DIEHL, Astor Antônio. Pesquisa em ciências sociais aplicadas: métodos e técnicas. São Paulo: Prentice Hall, 2004.

GIL, A. C. Como elaborar projetos de pesquisa. 3. ed. São Paulo: Atlas, 1991.

IBGE-Instituto Brasileiro de geografia e Estatística. Disponível:

https://cidades.ibge.gov.br/v4/brasil/mg/ouro-verde-de-minas/panorama Acesso:

06/06/2017.

MTO (2017) - Manual Técnico de Orçamento. Disponível:

www.orcamentofederal.gov.br/.../manual-tecnico/mto_2017, Ministério do

Planejamento, Desenvolvimento e Gestão. Secretaria de Orçamento

Federal. Manual técnico de orçamento MTO. Edição 2017. Brasília, 2016. Acesso:

$17 / 04 / 2017$

QUINTANA, Alexandre C; MACHADO, Daiane P.; Quaresma, Jozi C. da C.;

MENDES, Roselaine da C. Contabilidade Pública: de acordo com as Novas Normas Brasileiras de Contabilidade aplicadas ao setor público e ao Lei de Responsabilidade Fiscal. São Paulo: Atlas, 2011.

REIS, P. R. da C.; COSTA, T. de M. T. da; SILVEIRA, S. de F. R.. Receita pública e bem-estar social nos municípios mineiros emancipados no período de 1988 a

1997. READ. Revista eletrônica de administração, PortoAlegre, v. 19, n. 1, p. 6182, abr. 2013 . Disponível em:

<http://www.scielo.br/scielo.php?script=sci_arttext\&pid=S1413-

$23112013000100003 \&$ Ing=en\&nrm=iso >. Acesso em: 27 mar. 2017.

REZENDE, F. A. Finanças Públicas. 2. ed. São Paulo: Atlas, 2006.

SOSTMEIER, P. Planejamento e Aplicação do Orçamento no Governo

Municipal, Sapiranga/RS, 2012.

Disponivel: https://www.lume.ufrgs.br/bitstream/handle/10183/71505/000874597.pdf , Acesso: 17/04/2017

SOUZA, C. Governos locais e gestão de políticas sociais universais. São Paulo em Perspectiva, 18 p. 27-41, 2004. Disponível em: < http://www.scielo.br/pdf/spp/v18n2/a04v18n2.pdf>. Acesso em: 29. abr. 2017.

SUZART, J. A. S. O impacto da desvinculação de receitas nos gastos com educação da União. Rev. Adm. Pública — Rio de Janeiro 49(4):869-887, jul. /ago. 2015 
VERGARA, Sylvia C. Métodos de pesquisa em administração. 4. ed. São Paulo: Atlas, 2005.

VIEIRA, M. M. F.; ZOUAIN, D. M. Pesquisa qualitativa em administração. 2. ed. Rio de Janeiro: Editora FGV, 2006.

TOMIO, F. R. de L. A criação de municípios após a Constituição de 1988. Revista brasileira de Ciências Sociais, SãoPaulo, v. 17, n. 48, p. 61-89, fev. 2002

.Disponível em:http://www.scielo.br/pdf/rbcsoc/v17n48/13950.pdf>.Acesso em: 17. mar. 2017.

TOMIO, F.de L; ORTOLAN, M. Federalismo Predatório e Municipalização de Políticas Públicas Sociais. RAM- Revista de Administração Municipal. Rio de Janeiro, n. 284, p. 4-14, dez. 2015.

YIN, Robert K. Estudo de caso: planejamento e método. 2. ed. Porto Alegre: Brookman, 2001. 